\title{
ANALISIS NILAI EKONOMI USAHATANI BAWANG MERAH (Allium cepa L.) OFF SEASON DAN IN SEASON PADA LAHAN PASIR PANTAI (Studi Kasus di Desa Srigading Kecamatan Sanden Kabupaten Bantul DIY)
}

\author{
Arif Rahman Hakim, Rajiman, Rika Nalinda \\ Sekolah Tinggi Penyuluhan Pertanian Magelang \\ Jurusan Penyuluhan Pertanian Yogyakarta
}

\begin{abstract}
This study aims to determine the economic value of shallot cultivation offseason and in-season. It was conducted in Srigading Village, Sanden District, Bantul Regency on March to July 2017 using comparative study method. Sampling was chosen purposively for village and farmer groups. Samples of farmers taken using proportional sampling and snowball sampling method by 30 peoples. Statistical analysis using the t-test. The results of the study showed that off-season and in-season shallot farming was not significantly different and feasible economically. This is can be seen from the result of $t$-test of average shallot farmers income is $t$-count $<t$-table $(0,617<2,048)$ and sig. (2-tailed) $0,542>0,05$, the result of average difference test of farmers profit is $t$-count $<t$-table $(0,396<2,048)$ and sig. (2-tailed) 0,695>0,05, while the result of average difference test of business feasibility $(R / C$ ratio $)$ on shallotcultivation is $t$-count $<$-table $(0,150<2,048)$ and sig. (2-tailed) $0,882>0,05$. While analysis of farming is average revenue of shallot farmers off-season $R p$ 20.471.149,3 and in-season $R p$ 18.081.789,6, average profit of shallot farmers offseason $R p$ 11.922.949,9 and in-season $R p$ 10.520.079,9, and average business feasibility $(R / C$ ratio) of shallot farmers off-season 2,39 and in-season 2,33.
\end{abstract}

Keywords: shallot, sand land, off season, in season

\begin{abstract}
Abstrak: Kajian ini bertujuan untuk mengetahui nilai ekonomi budidaya bawang merah lahan pasir pantai off season dan in season. Kajian dilakukan di Desa Srigading Kecamatan Sanden Kabupaten Bantul bulan Maret-Juli 2017 dengan menggunakan metode kajian komparatif. Pengambilan sampel dipilih secara purposive untuk tingkat desa dan kelompok tani. Sampel petani diambil secara proporsional sampling dan snowball sampling sebanyak 30 orang. Analisis statistik menggunakan uji-t. Hasil kajian menunjukkan bahwa secara ekonomi usahatani bawang merah off season dan in season tidak berbeda nyata dan layak diusahakan. Hal ini dilihat dari hasil uji beda rata-rata penerimaan petani bawang merah yaitu t-hitung<t-tabel $(0,617<2,048)$ dan sig.(2-tailed) $0,542>0,05$, hasil uji beda rata-rata keuntungan petani bawang merah adalah t-hitung $<$ t-tabel $(0,396<2,048)$ dan sig. (2-tailed) $0,695>0,05$, dan hasil uji beda rata-rata kelayakan usaha ( $\mathrm{R} / \mathrm{C}$ ratio) budidaya bawang merah yaitu t-hitung $<\mathrm{t}$-tabel $(0,150<2,048)$ dan sig. (2-tailed) $0,882>0,05$. Sedangkan hasil analisis usahatani yaitu penerimaan rata-rata petani bawang merah off season $\mathrm{Rp} 20.471 .149,3$ dan in season $\mathrm{Rp}$ 18.081.789,6, keuntungan rata-rata petani bawang merah off season $\mathrm{Rp}$ 11.922.949,9 dan in season $\mathrm{Rp} 10.520 .079,9$, dan kelayakan usaha ( $\mathrm{R} / \mathrm{C}$ ratio) ratarata petani bawang merah off season 2,39 dan in season 2,33.
\end{abstract}

Kata kunci : bawang merah, lahan pasir pantai, off season, in season

\section{PENDAHULUAN}

Bawang merah (Allium cepa L.) merupakan salah satu komoditas sayuran yang potensial untuk dikembangkan di Indonesia. Bawang merah termasuk sayuran yang memiliki banyak kegunaan untuk dimanfaatkan sebagai rempahrempah pelengkap bumbu masak, bahan baku 
untuk industri makanan, dan dipakai sebagai obat tradisional.

Kebutuhan bawang merah nasional tahun 2008 - 2012 rata-rata sebanyak 990.767 ton (Ditjen Hortikultura 2004 dalam Iriani 2013). Produksi bawang merah nasional tahun 2014 2015 rata-rata sebanyak 1.231 .584 ton dengan produktivitas rata-rata nasional 10,14 ton/Ha dan luas panen rata-rata 121.415 hektar (Badan Pusat Statistik dan Direktorat Jenderal Hortikultura 2016).

Produksi bawang merah di sawah ternyata tidak dapat dilakukan secara terus menerus. Hal ini sangat terkendala adanya perubahan musim hujan dan kemarau. Produksi tertinggi akan diperoleh saat panen raya yaitu bulan Juni dan Desember, sehingga di luar musim tersebut stok bawang merah mengalami kekurangan. Sedangkan musim tanam raya bawang merah jatuh pada bulan April dan Oktober (Rajiman, 2013).

Hingga kini ketersediaan bawang merah masih dibawah kebutuhan terutama pada musim hujan. Hal ini menyebabkan harga bawang merah di pasar sering melonjak, bahkan menyebabkan inflansi setiap tahun. Menurut data Kementerian Perdagangan (Ditjen PDN) tahun 2017, harga bawang merah sampai dengan bulan Maret 2017 masih berkisar antara Rp. 35.470 - Rp. 39.240, ini mengalami kenaikan dari 2 bulan sebelumnya. Hal ini disebabkan karena pada bulan Maret merupakan waktu off season (di luar musim panen) untuk budidaya bawang merah, sehingga terjadi kelangkaan stok bawang merah di pasaran yang mengakibatkan masih tingginya harga bawang merah dan fluktuasi harga yang belum stabil.

Untuk menstabilkan harga dan penyediaan stok bawang merah di pasaran maka perlu adanya peningkatan produksi untuk mengimbangi volume kebutuhan yang cenderung meningkat setiap tahunpada waktu off season. Peningkatan produksi bawang merah pada waktu off season (luar musim) sangat penting, akan tetapi faktor cuaca menjadi kendala dimana intensitas hujan yang tinggi dapat menyebabkan terganggunya fotosintesis dan tingginya tingkat serangan penyakit yang menyebabkan produksi menurun (Purba dan Astuti, 2013).Oleh karena itu perlu adanya pengembangan sentra bawang merah baru di lahan kering,karena usahatani bawang merah di lahan sawah pada musim hujan dianggap tidak efisien dan tidak menguntungkan.

Budidaya bawang merah dilahan pasir pantai merupakan upaya untuk menyediakan bawang merah sepanjang tahun. Lahan pasir pantai dimungkinkan untuk memperoduksi bawang merah sampai 4 kali musim tanam.Selain itu, lahan pasir pantai memiliki beberapa kelebihan untuk lahan pertanian yang luas, datar, jarang banjir, sinar matahari melimpah, dan kedalaman air tanahnya dangkal. Selain itu persiapan lahan pasir pantai cukup sederhana hanya dengan membuat bedengan tidak dibuat parit-parit yang dalam, sehingga akan terjadi efesiensi biaya dari pengolahan tanah (Rajiman, 2010).

Program peningkatan produksi bawang merah juga dilakukan oleh Pemerintah Daerah Istimewa Yogyakarta dengan memanfaatkan lahan pasir. Sesuai dengan program pembangunan pertanian Daerah Istimewa Yogyakarta, pemanfaatan lahan pasir pantai selatan bertujuan mewujudkan pertanian tangguh yang dapat mendukung industri yang kuat dan maju serta pola pembinaan komoditas sektor pertanian yang berorientasi agribisnis, berwawasan lingkungan yang berkelanjutan (Bappeda DIY 2001, dalam Marla 2016).

Daerah yang termasuk dalam program pembangunan pertanian Daerah Istimewa Yogyakarta di lahan pasir adalah kabupaten Bantul dengan komoditas unggulan yaitu bawang merah. Sentra bawang merah Kabupaten Bantul berada di Kecamatan Sanden. Kecamatan Sanden memiliki lahan pasir dengan luas 294,6 hektar yang tersebar di 3 desa yaitu Desa Gadingsari seluas 90 hektar, Desa Gadingharjo seluas 18,6 hektar, dan Desa Srigading seluas 186 hektar (BPP, 2016).

Di desa Srigading terdapat dua kelompok tani yang sudah lama mengusahakan lahan pasir pantai terutama dalam budidaya bawang merah di luar musim (off season). Dua kelompok tani tersebut berada di dusun Tegalrejo yaitu kelompok tani Pasir Makmur dan kelompok tani Manunggal (BPP,2016). Kaitannya dengan hal tersebut maka perlu dilakukan kajian tentang Analisis nilai ekonomi usahatani bawang merah off season dan in season di lahan pasir pantai.

Kajian ini bertujuan untuk mengetahui perbedaan antara nilai ekonomi budidaya 
bawang merah lahan pasir pantaioff season dengan in season.

\section{METODE PENELITIAN}

Kajian dilaksanakan pada bulan Maret - Juli 2017 di Desa Srigading Kecamatan Sanden Kabupaten Bantul DIY. Pemilihan lokasi dilakukan secara purposive.

Berdasarkan tujuannya jenis kajian dalam penelitian ini adalah kajian komparatif. Penelitian komparatif merupakan penelitian yang bersifat membandingkan persamaan dan perbedaan dua atau lebih fakta-fakta dan sifatsifat objek yang diteliti berdasarkan kerangka pemikiran tertentu.

Data yang digunakan dalam penelitian inimerupakan data sekunder yang diperoleh daridari BPP, Kecamatan, Kantor desa, Dinas Pertanian atau instansi terkait. Pengumpulan data primer dilakukan melalui metode wawancara langsung dengan responden petanibawang merah lahan pasir dengan bantuan kuesioner.

Responden petani bawang merah ditentukansecara Proportional Sampling dan Snowball Sampling. Jumlah data responden yangdigunakan dalam penelitian ini sebanyak 30petani bawang merah di masingmasingkelompok tani.Metode analisis data yang digunakan dalam penelitian ini adalah analisis kuantitatif. Analisis kuantitatif digunakan untuk menganalisis nilai ekonomi (penerimaan, keuntungan, $\mathrm{R} / \mathrm{C}$ ratio) usahatani bawangmerah lahan pasir pantai off season dan in season. Nilai ekonomi usahatani dalam penelitian ini didefinisikan sebagai seluruh barang dan jasa dalam usahatani yang secara langsung memberikan manfaat berupa pendapatan usahatani. Dalam penelitian ini juga dihitung keuntungan usahatani yang merupakan selisih antara penerimaan usahatani dengan biaya total atau biaya yang secara aktual dikeluarkan olehpetani. Penerimaan usahatani berasal dari penjualan umbi bawang merah. Biaya yang dikeluarkan petani meliputi biayabenih, biaya pupuk, biaya obat-obatan, upahtenaga kerja, dan biaya lain yangterkait.

\section{HASIL DAN PEMBAHASAN}

\section{Karakteristik Responden}

Karakteristik dari masing-masing petani berbeda-beda dan dapat mempengaruhi keragaan usaha tani dari aspek teknik budidaya sehingga akan berpengaruh juga terhadap produksi yang dihasilkan. Karakteristik petani responden yang dianggap penting untuk diketahui diantaranya umur, tingkat pendidikan, status dalam kelompok tani, pengalaman usahatani, dan luas penggunaan lahan.

Tabel 1 menunjukkan bahwa jenjang umur petani responden di Desa Srigading Kecamatan Sanden Kabupaten Bantul beragam. Umur petani responden didominasi umur antara $15-64$ tahun sebanyak 26 orang atau $86,67 \%$ dari 30 petani sampel. Hasil tersebut menunjukkan bahwa usahatani bawang merah lahan pasir di desa Srigading masih dilakukan oleh petani pada usia produktif. Usia produktif adalah usia yang paling tepat untuk menjalankan aktifitas-aktifitas bekerja seperti bertani karena secarafisik masih baik, memiliki semangat tinggi danadanya kewajiban untuk menghidupi keluarga.

Dilihat dari tingkat pendidikan formal, pendidikan petani responden sangat beragam, tingkat pendidikan rata-rata petani responden yaitu SLTA/ sederajat dengan jumlah 15 orang atau $50 \%$ dari jumlah sampel. Tingkat pendidikan

akan mempengaruhi cara berpikir petani dantingkat penyerapan teknologi dan ilmu pengetahuan. Status responden dalam kelompok tani perlu diketahui untuk melihat keterlibatan petani responden dalam kelompok tani. Status petani responden dalam kelompok tani didominasi oleh anggota kelompok tani sebanyak 25 orang petani responden atau 83,33 $\%$ dari jumlah sampel.

Pengalaman usahatani berkaitan dengan berapa lama petani melakukan kegitan usahatani bawang merah di lahan pasir. Pengalaman tersebut selanjutnya akan mempengaruhi sebagian besar sikap dan tindakan petani dalam pengambilan keputusan usahataninya. Rata-rata pengalaman usahatai bawang merah di lahan pasir pantai oleh petani responden yaitu > 10 tahun sebanyak 25 responden atau 83,33\%dari jumlah sampel. 
Arif Rahman Hakim, Rajiman, Rika Nalinda: Analisis Nilai Ekonomi Usahatani...

Tabel 1. Karakteristik Petani Bawang Merah Lahan Pasir di Desa Srigading

\begin{tabular}{|c|c|c|c|}
\hline No & Uraian & Jumlah (orang) & Persentase (\%) \\
\hline \multirow[t]{3}{*}{1} & Umur & & \\
\hline & - 15-64 tahun & 26 & 86,67 \\
\hline & - $\geq 65$ tahun & 4 & 13,33 \\
\hline \multirow[t]{4}{*}{2} & Tingkat Pendidikan & & \\
\hline & - $\quad$ SLTA/ sederajat & 15 & 50 \\
\hline & - $\mathrm{SD}$ & 9 & 30 \\
\hline & - SLTP & 6 & 20 \\
\hline \multirow[t]{5}{*}{3} & Status Dalam Kelompok Tani & & \\
\hline & - Ketua & 2 & 6,67 \\
\hline & - Sekertaris & 1 & 3,33 \\
\hline & - Bendahara & 2 & 6,67 \\
\hline & - Anggota & 25 & 83,33 \\
\hline \multirow[t]{3}{*}{4} & Pengalaman Usahatani & & \\
\hline & - $<10$ tahun & 5 & 16,67 \\
\hline & - $>10$ tahun & 25 & 83,33 \\
\hline \multirow[t]{3}{*}{5} & Luas Penggunaan Lahan & & \\
\hline & - $\quad<1.000 \mathrm{~m}^{2}$ & 18 & 60 \\
\hline & - $>1.000 \mathrm{~m}^{2}$ & 12 & 40 \\
\hline
\end{tabular}

Sumber: Olahan Data Primer Tahun 2017

Penguasaan lahan untuk budidaya bawang merah lahan pasir relatif kecil yaitu masih dibawah satuhektar. Sebagian besar petani bawang merah lahan pasir pantai di Desa Srigading mengusahakanbawang merah pada lahan dibawah $1.000 \mathrm{~m}^{2}$ yaitu sebanyak 18 orang petani responden atau $60 \%$ dari jumlah responden.

\section{Analisis Nilai Ekonomi Usahatani Bawang Merah Lahan Pasir Pantai}

Analisis nilai ekonomi usahatani bawang merah lahan pasir pantai di desa Srigading, Kecamatan Sanden, Kabupaten Bantul disajikan padaTabel 2.

Berdasarkan hasil analisis nilai ekonomi usahatani bawang merah off season dan in season diperoleh bahwa Selisih biaya sarana produksi budidaya bawang merah off season lebih besar Rp 1.112.591 dari pada budidaya bawang merah in season, dimana total biaya sarana produksibudidaya bawang merah off season sebesar $\mathrm{Rp} 6.200 .950,8 / 1.000 \mathrm{~m}^{2}$ dan total biaya sarana produksibudidaya bawang merah in season sebesar Rp 5.088.359,8/ 1.000 $\mathrm{m}^{2}$. Dari hasil analisis biaya usahatani bawang merah lahan pasir, biaya kebutuhan benih merupakan biaya terbeser yang dikeluarkan oleh petani sebesar $43,6-52,9 \%$ dari biaya total.

Penerimaan petani bawang merah off seasonRp 20.471.149,3 lebih besar dari in season $\mathrm{Rp}$ 18.081.789,6 dengan selisih sebesar Rp 2.389.359,7 atau $6.19 \%$ dari total penerimaan rata-rata petani responden. Besarnya selisih penerimaan rata-rata antara petani bawang merah off season lahan pasir pantai dengan petani bawang merah in seasonlahan sawah disebabkan oleh lebih tingginya harga jual rata-rata bawang merah off season lahan pasir pantai sebesar Rp 40.730,5/ kg jika dibandingkan dengan harga jual ratarata bawang merah in season lahan sawah sebesar Rp 10.710,53/ kg. Tingginya harga jual bawang merah off season pada lahan pasir pantai dipengaruhi oleh kurangnya pasokan bawang merah di pasaran karena kurangnya petani yang melakukan budidaya bawang merah pada waktu off season (musim hujan) yang berdampak pada tingginya permintaan bawang merah sehingga akan menyebabkan tingginya harga jual bawang merah.

Sedangkan keuntungan petani bawang merah off season Rp 11.922.949,9 lebih besar dari in season $\mathrm{Rp} 10.520 .079,9$ dengan selisih sebesar Rp 1.402.870 atau 6,25\% dari total keuntungan rata-rata petani responden. 
Arif Rahman Hakim, Rajiman, Rika Nalinda: Analisis Nilai Ekonomi Usahatani...

Tabel 2. Rata-Rata Biaya, Penerimaan, Keuntungan, dan R/C ratio Usahatani Bawang Merah Lahan Pasir Pantai Off Season dan In SeasonDesa Srigading per $1.000 \mathrm{~m}^{2}$

\begin{tabular}{|c|c|c|c|}
\hline \multirow{2}{*}{ No } & \multirow{2}{*}{ Uraian } & Budidaya Off Season & \multirow{2}{*}{$\begin{array}{c}\text { Budidaya In Season } \\
\text { Nilai (Rp) }\end{array}$} \\
\hline & & Nilai (Rp) & \\
\hline \multirow[t]{28}{*}{ A } & Biaya & & \\
\hline & 1 Biaya Tetap & & \\
\hline & a.Biaya Penyusutan Alat & $149.479,3$ & $124.789,1$ \\
\hline & Jumlah & $149.479,3$ & $124.789,1$ \\
\hline & Biaya Variabel & & \\
\hline & a.Biaya Saprodi & & \\
\hline & Benih (kg) & $4.521 .145,7$ & $3.297 .528,3$ \\
\hline & Olah Lahan & $173.348,4$ & $133.128,1$ \\
\hline & Mulsa (rol) & $106.051,6$ & $89.428,6$ \\
\hline & Pupuk (kg/l) & $576.807,6$ & $603.674,7$ \\
\hline & Pestisida $(\mathrm{kg} / \mathrm{l})$ & $451.427,8$ & $570.667,3$ \\
\hline & $\mathrm{BBM}(\mathrm{kg} / \mathrm{l})$ & $372.169,7$ & $393.932,8$ \\
\hline & Jumlah & $6.200 .950,8$ & $5.088 .359,8$ \\
\hline & b.Biaya Tenaga Kerja & & \\
\hline & Buat Bedeng (HOK) & $157.708,2$ & $147.517,0$ \\
\hline & Sebar Pupuk (HOK) & $57.385,2$ & $52.502,3$ \\
\hline & Pasang Mulsa (HOK) & $35.476,2$ & $53.928,6$ \\
\hline & Penanaman (HOK) & $153.669,1$ & $143.072,6$ \\
\hline & POPT (HOK) & $227.225,4$ & $203.591,8$ \\
\hline & Penyiangan (HOK) & $103.313,4$ & $92.777,8$ \\
\hline & Penyiraman (HOK) & $544.491,7$ & $633.894,6$ \\
\hline & Panen (HOK) & $189.270,2$ & $286.848,1$ \\
\hline & Angkut Hasil & $106.398,9$ & $103.866,2$ \\
\hline & Potong Daun (Kg) & $96.952,4$ & $630.561,9$ \\
\hline & Ikat Daun $(\mathrm{Kg})$ & $525.878,7$ & \\
\hline & Jumlah & 2.197.769,3 & $2.348 .560,9$ \\
\hline & Jumlah $2 a+2 b$ & 8.398.720,1 & 7.436.920,7 \\
\hline & Jumlah $1+2$ & 8.548.199,4 & 7.561.709,7 \\
\hline B & Hasil (kg) & 502,6 & 847,2 \\
\hline $\mathrm{C}$ & Harga (Rp) & $40.730,5$ & 21.343 \\
\hline $\mathrm{D}$ & Penerimaan (Rp) & $20.471 .149,3$ & $18.081 .789,6$ \\
\hline $\mathrm{E}$ & Keuntungan (Rp) & $11.922 .949,9$ & $10.520 .079,9$ \\
\hline $\mathrm{F}$ & $\mathrm{R} / \mathrm{C}$ ratio & 2,39 & 2,33 \\
\hline
\end{tabular}

Sumber: Olahan Data Primer Tahun 2017

Besarnya selisih keuntungan rata-rata petani bawang merah off season lahan pasir dengan in season dipengaruhi oleh lebih besarnya penerimaan yang diperoleh oleh petani bawang merah off season dari pada penerimaan petani in season. Dimana keuntungan didapat dari total penerimaan dikurangi dengan total biaya

Hasil analisis kelayakan usaha (R/C ratio) rata-rata antara petani bawang merah off season 2,39, lebih besar dari in season 2,33 dengan selisih sebesar 0,06 atau 1,27\% dari total $\mathrm{R} / \mathrm{C}$ ratio rata-rata petani responden. Besarnya selisih nilai $\mathrm{R} / \mathrm{C}$ ratio antara budidaya bawang merah off season dengan in seasonsangat dipengaruhi oleh besarnya penerimaan yang diperoleh petani. Dimana nilai $\mathrm{R} / \mathrm{C}$ ratio diperoleh dari hasil dari penerimaan dibagi total biaya.

\section{Uji Beda Rata-Rata Usahatani Bawang Merah Lahan Pasir}

Hasil uji beda rata-rata penerimaan, keuntungan, kelayakan usaha (R/C ratio) antara budidaya bawang merah off season dengan budidaya bawang merah in season menggunakan program SPSS dapat dilihat padaTabel 3 . 
Arif Rahman Hakim, Rajiman, Rika Nalinda: Analisis Nilai Ekonomi Usahatani...

Tabel 3. Uji Beda Rata-rata Penerimaan, Keuntungan, dan R/C ratio

\begin{tabular}{|c|c|c|c|c|c|c|}
\hline \multirow{2}{*}{ No } & \multirow{2}{*}{ Uraian } & \multicolumn{2}{|c|}{ Hasil Uji Beda } & \multirow{2}{*}{ t-Tabel $5 \%$} & \multirow[t]{2}{*}{ Sig. Pembanding } & \multirow[t]{2}{*}{ Ket. } \\
\hline & & t-hitung & Sig. (2-tailed) & & & \\
\hline 1 & Penerimaan & 0,617 & 0,542 & 2,048 & 0,05 & ns \\
\hline 2 & Keuntungan & 0,396 & 0,695 & 2,048 & 0,05 & ns \\
\hline 3 & $\mathrm{R} / \mathrm{C}$ ratio & 0,150 & 0,882 & 2,048 & 0,05 & ns \\
\hline
\end{tabular}

Sumber: Olahan Data Primer Tahun 2017

Hasil uji beda rata-ratamenunjukkan bahwa penerimaan petani bawang merah yaitu t-hitung 0,617 dan sig. (2-tailed) 0,542 dimana hasil sig. (2-tailed) pada taraf beda nyata $5 \%$ dengan tingkat kebenaran $95 \%$ adalah 0,542> 0,05 maka H0 diterima, begitupun jika dibandingkan nilai t-hitung 0,617dengan nilai t-Tabel sebesar 2,048 (5\%) maka $0,617<2,048$ yang artinya H0 diterima, sehingga dapat disimpulkan bahwa tidak ada perbedaan yang signifikan antara rata-rata penerimaan petani bawang merah off season dengan petani bawang merah in season. Sedangkan hasil uji beda rata-rata keuntungan petani bawang merah adalah t-hitung 0,396 dan sig. (2-tailed) 0,695 dimana hasil sig. (2tailed) pada taraf beda nyata $5 \%$ dengan tingkat kebenaran $95 \%$ adalah $0,695>0,05$ maka $\mathrm{H} 0$ diterima, begitupun jika dibandingkan dengan nilai t-Tabel sebesar 2,048 (5\%) maka $0,396<2,048$ yang artinya H0 diterima, sehingga dapat disimpulkan bahwa tidak ada perbedaan yang signifikan antara rata-rata keuntungan petani bawang merah off season dengan petani bawang merah in season. Hasil uji beda rata-rata kelayakan usaha (R/C ratio) budidaya bawang merah yaitu t-hitung 0,150 dan sig. (2-tailed) 0,882 dimana hasil sig. (2tailed) pada taraf beda nyata $5 \%$ dengan tingkat kebenaran $95 \%$ adalah $0,882>0,05$ maka $\mathrm{H} 0$ diterima, begitupun jika dibandingkan dengan nilai t-Tabel sebesar 2,048 (5\%) maka $0,150<2,048$ yang artinya H0 diterima, sehingga dapat disimpulkan bahwa tidak ada perbedaan yang signifikan antara rata-rata nilai $\mathrm{R} / \mathrm{C}$ ratio budidaya bawang merah off season dengan budidaya bawang merah in season yang berarti budidaya bawang merah off season dan budidaya bawang merah in season sama-sama layah diusahakan.

\section{KESIMPULAN DAN SARAN}

\section{Kesimpulan}

Berdasarkan hasil kajian dengan judul analisis nilai ekonomi usahatani bawang merah (Allium cepa L.) off seasondan in seasonpada lahan pasir pantai dapat disimpulkan bahwa nilai ekonomi(penerimaan, keuntungan, $\mathrm{R} / \mathrm{C}$ ratio) usahatani bawang merah off season dan in season memiliki tidak berbeda nyata. Hal ini dilihat dari hasil uji beda rata-rata penerimaan petani bawang merah yaitu $\mathrm{t}-$ hitung <t-tabel $\quad(0,617<2,048) \quad$ dan sig. $(2-$ tailed) $0,542>0,05$, hasil uji beda rata-rata keuntungan petani bawang merah adalah $\mathrm{t}$ hitung $<\mathrm{t}$-tabel $\quad(0,396<2,048) \quad$ dan sig. $(2-$ tailed) $0,695>0,05$, dan hasil uji beda rata-rata kelayakan usaha ( $\mathrm{R} / \mathrm{C}$ ratio) budidaya bawang merah yaitu t-hitung $<\mathrm{t}$-tabel $\quad(0,150<2,048)$ dan sig.(2-tailed) 0,882>0,05. Sedangkan hasil analisis usahatani yaitu penerimaan rata-rata petani bawang merah off season $\mathrm{Rp}$ 20.471.149,3 dan in season $\mathrm{Rp} 18.081 .789,6$, keuntungan rata-rata petani bawang merah off season $\mathrm{Rp} 11.922 .949,9$ dan in season $\mathrm{Rp}$ 10.520.079,9, dan kelayakan usaha ( $\mathrm{R} / \mathrm{C}$ ratio) rata-rata petani bawang merah off season 2,39 dan in season 2,33.

\section{Saran}

Perlu peningkatan motivasi dan sikap petani agar mau membudidayakan bawang merah lahan pasir pantai off season karena lebih menguntungkan sehingga layak untuk diusahakan.Perlunya penelitian lanjutan yang lebih mendalam terhadap pendapatan petani bawang merah lahan pasir pantai off season untuk masing-masing varietas bawang merah.

\section{DAFTAR PUSTAKA}

Aldila FH, Farianti H, dan Tinaprilla N. 2015. Analisis Profitabilitas Usahatani Bawang Merah Berdasarkan Musim Di Tiga Kabupaten Sentra Produksi Di 
Indonesia. Jurnal, Institut Pertanian Bogor. 11. 2. $249-260$.

Mohammad Ali dan Mohammad Asrori, 2010. Psikologi Remaja (Perkembangan Peserta Dididik). PT Bumi Aksara. Jakarta.

Apriyani H. 2015. Motivasi Petani Penangkar Dalam Pengembangan Benih Bawang Merah (Allium cepa L.) Di Kecamatan Sanden Kabupaten Bantul DIY. KIPA. Sekolah Tinggi Penyuluhan Pertanian Magelang Jurluhtan Yogyakarta.

Budiharsono. 2002. Teknik Analisis Pembangunan Wilayah Pesisir dan Lautan. Pradnya Paramita. Jakarta.

Bungin B. 2005. Metodologi Penelitian Kuantitatif : Komunikasi, Ekonomi, dan Kebijakan Publik serta Ilmu-Ilmu Sosial Lainnya. Prenada Media Group. Jakarta.

BPP Balai Penyuluhan Pertanian Kecamatan Sanden. 2016. Programa PenyuluhanPertanian, Perikanan dan Kehutanan. Yogyakarta (ID): BPP Kecamatan Sanden.

BPS Badan Pusat Statistik dan Direktorat Jenderal Hortikultura. 2016. Produksi Bawang Merah Menurut Provinsi, 2011 2015. Jakarta (ID): Badan Pusat Statistik Jakarta.

BPS Badan Pusat Statistik dan Direktorat Jenderal Hortikultura. 2016. Produktivitas Bawang Merah Menurut Provinsi, 2011-2015. Jakarta (ID): Badan Pusat Statistik Jakarta.

Ditjen PDN. 2017. Tabel Harga Kebutuhan Pokok Nasional. Kementerian Perdagangan. www.kemendag.go.id/id/economicprofile/prices/national-pricetable.Diakses Pada Tanggal 1 April 2017 pukul 09.00 Wib di Yogyakarta.

Hernanto F. 1989. Ilmu Usaha Tani. Penebar Swadaya. Jakarta.
Iriani E. 2013. Prospek pengembangan inovasi teknologi bawang merah di lahan suboptimal (lahan pasir) dalam upaya peningkatan pendapatan petani. J Penelit Pembang Jawa Tengah. 11(2);231-243.

Marla DH. 2016. Analisis Pendapatan Usahatani Bawang Merah Di Lahan Pasir Kecamatan Sanden Kabupaten Bantul Yogyakarta. Skripsi. Institut Pertanian Bogor.

Mubyarto, 1989. Pengantar Ekonomi Pertanian.LP3ES, Jakarta

Nazir M. 2014. Metode Penelitian. Ghalia Indonesia. Bogor.

Nazir M. 2011. Metode Penelitian. Ghalia Indonesia. Bogor.

Nugiyantoro B. 2012. Statistik Terapan Untuk Penelitian Ilmu-Ilmu Sosial. Universitas Gajah Mada Press. Yogyakarta.

Nurdiani N. 2014. Teknik Sampling Snowball Dalam Penelitian Lapangan.Comtech, Journal BINUS University. 5(2); 1110 1118.

Pitojo, Setijo. 2003. Seri Penangkaran Benih Bawang Merah. Kanisius. Yogyakarta

Purba R dan Astuti Y. 2013. Paket Teknologi Bawang Merah Di Luar Musim Tanam Di Pandeglang Banten. Jurnal. Balai Pengkajian Teknologi Pertanian Banten. 15(2); $105-113$.

Rajiman. 2013. Kiat Sukses Pengelolaan Lahan Pasir Untuk Bawang Merah. Deepublish. Yogyakarta.

Rajiman. 2010. Pemanfaatan Bahan Pembenah Tanah Lokal Dalam Upaya Peningkatan Produksi Benih Bawang Merah Di Lahan Pasir Pantai Kulon Progo. Disertasi. Universitas Gajah Mada. Yogyakarta.

Samadi B dan Cahyono B. 1996. Intensifikasi Budidaya Bawang Merah. Kanisius. Ygyakarta 
Arif Rahman Hakim, Rajiman, Rika Nalinda: Analisis Nilai Ekonomi Usahatani...

Silalahi, Ulber. 2012. Metode Penelitian Pendidikan. Alfabeta. Bandung.

Siregar H. 2009. Analisis Nilai Ekonomi Dan Tingkat Kunjungan Di Obyek Wisata Alam Air Terjun Sipiso-Piso Kabupaten Karo. Skripsi. Universitas Sumatra Utara. Medan.

Soekartawi. 1995. Analisis Usaha Tani.Universitas Indonesia Press. Jakarta

Soekartawi. 1986. Ilmu Usaha Tani dan Penelitian Untuk Pengembangan Petani Kecil. Universitas Indonesia Press. Jakarta.

STPP. 2017. Petunjuk Teknis Karya Ilmiah Penugasan Akhir (KIPA). STPP. Yogyakarta.
Sugiyono. 2014. Metode Penelitian Pendidikan. Alfabeta. Bandung.

Sugiyono. 2003. Metode Penelitian Bisnis. Pusat Bahasa Depdiknas. Bandung.

Sujono. 2013. Metode Penyuluhan Pertanian. CV Prineka. Yogyakarta.

Suwandi. 2013. Teknologi Bawang Merah OffSeason:Strategi dan Implementasi Budidaya.Bandung, Indonesia (ID): Balai Penelitian Tanaman Sayuran.

Widodo AS. 2015. Pengaruh Sistem Pengairan Dan Tanaman Penahan AnginTerhadap Risiko Produksi Usahatani Bawang Merah Di Lahan Pantai Kabupaten Bantul. Prosiding Seminar Nasional Hasil Penelitian Pertanian.Fakultas Pertanian Universitas Gadjah Mada. Yogyakarta. 